\title{
LA-UR-16-27341
}

Approved for public release; distribution is unlimited.

Title: $\quad$ Comparison of femtosecond and nanosecond laser ablation inductively coupled plasma mass spectrometry for uranium isotopic measurements

Author(s):

Havrilla, George Joseph

McIntosh, Kathryn Gallagher

Judge, Elizabeth

Dirmyer, Matthew R.

Campbell, Keri

Gonzalez, Jhanis J.

Intended for: Report

Issued:

2016-10-20 (rev.1) 
Disclaimer:

Los Alamos National Laboratory, an affirmative action/equal opportunity employer, is operated by the Los Alamos National Security, LLC for the National Nuclear Security Administration of the U.S. Department of Energy under contract DE-AC52-06NA25396. By approving this article, the publisher recognizes that the U.S. Government retains nonexclusive, royalty-free license to publish or reproduce the published form of this contribution, or to allow others to do so, for U.S. Government purposes. Los Alamos National Laboratory requests that the publisher identify this article as work performed under the auspices of the U.S. Department of Energy. Los Alamos National Laboratory strongly supports academic freedom and a researcher's right to publish; as an institution, however, the Laboratory does not endorse the viewpoint of a publication or guarantee its technical correctness. 


\title{
HPRR.01.02.04.23 Femtosecond LAICPMS for Nuclear Fuel Characterization
}

\section{Comparison of femtosecond and nanosecond laser ablation inductively coupled plasma mass spectrometry for uranium isotopic measurements}

\author{
George J. Havrilla ${ }^{1}$, Kathryn McIntosh ${ }^{1}$, Elizabeth Judge ${ }^{1}$, Matthew Dirmyer ${ }^{1}$, Keri Campbell ${ }^{1}$, \\ Jhanis Gonzalez ${ }^{2}$ \\ ${ }^{1}$ Los Alamos National Laboratory, Chemistry Division, Los Alamos, NM 87544 \\ ${ }^{2}$ Applied Spectra Inc., 46661 Fremont Blvd., Fremont, CA 94538
}

\begin{abstract}
Feasibility tests were conducted using femtosecond and nanosecond laser ablation inductively coupled plasma mass spectrometry for rapid uranium isotopic measurements. The samples used in this study consisted of a range of pg quantities of known 235/238 U solutions as dried spot residues of $300 \mathrm{pL}$ drops on silicon substrates. The samples spanned the following enrichments of ${ }^{235} \mathrm{U}: 0.5,1.5,2,3$, and $15.1 \%$. In this direct comparison using these particular samples both pulse durations demonstrated near equivalent data can be produced on either system with respect to accuracy and precision. There is no question that either LA-ICP-MS method offers the potential for rapid, accurate and precise isotopic measurements of U10Mo materials whether DU, LEU or HEU. The LA-ICP-MS equipment used for this work is commercially available. The program is in the process of validating this work for large samples using center samples strips from Y-12 MP-1 LEU-Mo Casting \#1.
\end{abstract}

\section{INTRODUCTION}

The United States government is committed to further strengthening nuclear security and nonproliferation in order to reduce the threat of terrorists acquiring nuclear material. To meet this important mission, the US Department of Energy/National Nuclear Security Agency's Office of Material Management and Minimization (M3) Reactor Conversion Program minimizes the use of highly enriched uranium (HEU) in civilian applications by working with governments and facilities around the world to convert research reactors to the use of non-weapons-usable lowenriched uranium (LEU) fuels. Each reactor converted not only eliminates the need for HEU at civilian sites, but also reduces the amount of HEU being manufactured, stored, and transported, where it is at its most vulnerable. In instances where suitable LEU fuels do not exist for particular reactors to convert, the M3 Reactor Conversion Program contributes to the development of new LEU fuels. Currently, the M3 Reactor Conversion Program is committed to developing a high-density U-Mo LEU fuel that will be able to convert high performance research reactors while establishing an efficient and economic fabrication capability to make the fuel. As such the LEU fuel requires the ${ }^{235} \mathrm{U}$ content to be below $20 \mathrm{wt} \%$ to qualify as LEU. In order to insure the LEU requirement is met, an alternative method other than radiometric and thermal ionization mass spectrometry based methods for measuring the uranium isotope ratio is being considered for rapid, accurate and quantitative measurement of this critical parameter for the U10Mo fuel. [1] One method being considered for measurement of the 235/238 U ratio is laser ablation inductively coupled plasma mass spectrometry (LA-ICP-MS). [2] This method utilizes short pulses (nanosecond $10^{-9} \mathrm{~s}$ and femtosecond, $10^{-15} \mathrm{~s}$ ) of laser light to ablate material from the 
surface of a sample. The ablated material is carried into the inductively coupled plasma where the ablated particles are vaporized and ionized, which are then swept into the mass spectrometer detector. [3,4] The mass spectrometer is an ideal means to measure isotopic composition in a process environment. LA-ICP-MS measurements can be done rapidly and accurately with no sample preparation required and thereby keep the process moving forward. This report compares the use of both nanosecond (ns) and femtosecond (fs) LA-ICP-MS for measuring the uranium isotopic ratio for uranium. This demonstration uses selected enriched 235 uranium compositions, the test materials were dried residues of known 235/238 U solution compositions deposited on silicon substrates. This sample preparation approach provided ease of preparation of a range of $235 / 238 \mathrm{U}$ ratios as well as maintaining the mass of ${ }^{235} \mathrm{U}$ present in the samples to well below regulated levels. These low mass levels of ${ }^{235} \mathrm{U}$ allowed us to move samples within LANL as well as sending samples to our external collaborator without transportation issues.

\section{EXPERIMENTAL}

Sample preparation

Table 1 shows the calculated total mass of uranium deposited as well as the isotopic

Table 1. Calculated isotopic and total U mass composition for each solution prepared by TIPS.

\begin{tabular}{|c|c|c|c|c|c|c|c|c|}
\hline \multirow[t]{2}{*}{ Description (nominal values) } & \multirow{2}{*}{$\begin{array}{c}\text { Concentration } \\
\text { Total U }\end{array}$} & \multicolumn{4}{|c|}{ Isotope mass fraction } & $\begin{array}{c}\text { Mass per } \\
\text { spot }\end{array}$ & $\begin{array}{c}\text { Mass per } \\
\text { array }\end{array}$ & $\begin{array}{c}\text { Mass per } \\
\text { set }\end{array}$ \\
\hline & & [234 U] & {$[235 \mathrm{U}]$} & {$[236 \mathrm{U}]$} & {$[238 \mathrm{U}]$} & \multicolumn{3}{|c|}{ Total U } \\
\hline & ppm & & & & & \multicolumn{3}{|c|}{ pg } \\
\hline (A) Uranium (Depleted) from SPEX stock $10 \mathrm{mg} / \mathrm{mL}$ & 25.0 & & 0.003 & & 0.997 & 7.50 & 750 & 1500 \\
\hline (B) Uranium (Depleted)-U3O8, 0.5\% & 25.9 & 0.0000334 & 0.005 & 0.0000117 & 0.994955 & 7.77 & 777 & 1554 \\
\hline (C) Uranium (Enriched) Isotopic-U3O8, 1.5\% & 18.8 & 0.0000836 & 0.015132 & 0.000163 & 0.98462 & 5.64 & 564 & 1128 \\
\hline (D) Uranium (Enriched) Isotopic-U3O8, 2\% & 30.3 & 0.0001703 & 0.020011 & 0.0001169 & 0.979702 & 9.09 & 909 & 1818 \\
\hline (E) Uranium (Enriched) Isotopic-U3O8, 3\% & 26.6 & 0.0002732 & 0.030032 & 0.00000594 & 0.969689 & 7.98 & 798 & 1596 \\
\hline (F) Uranium (Enriched) Isotopic-U308, 15\% & 41.8 & 0.000978 & 0.15143 & 0.000656 & 0.84693 & 12.54 & 1254 & 2508 \\
\hline
\end{tabular}

composition of each sample. The solutions were deposited onto $25 \times 25 \mathrm{~mm}$ silicon substrates for ASI and onto $13 \times 70 \mathrm{~mm}$ silicon substrates for LANL using the TIPS device [5]. The volume for each droplet was $300 \mathrm{pL}$, with $500 \mu \mathrm{m}$ spacing between deposits into a $10 \mathrm{x} 10$ array,

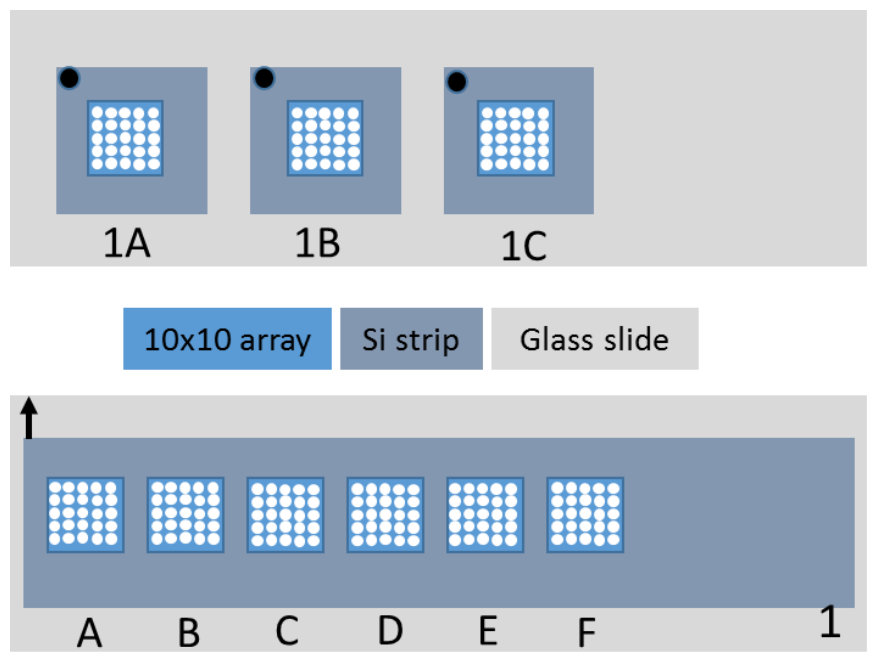

Figure 1. Cartoon illustration of ASI (top) and LANL (bottom) deposition arrays. 
producing 100 dried residues for each sample. The solutions were deposited from the lowest enrichment to the highest (A-F) starting with the depleted U solution at 0.003 mass fraction of $235 \mathrm{U}$ up to 0.15143 mass fraction of ${ }^{235} \mathrm{U}$. Two deposit arrays of each of the six solutions were prepared for a total of 12 arrays containing 100 spots each. A cartoon illustrating the ASI and LANL deposits is shown in Figure 1. The deposits were done in order from A to F with all 4 replicates being completed before switching the solution to the next one. The same dispenser was used throughout and rinsed 3 times in between solutions. As can be seen from the mass per spot column in Table 1, the total $\mathrm{U}$ mass per spot ranges from $\sim 6$ to $\sim 13 \mathrm{pg}$. This means for sample B with only $0.5 \%{ }^{235} \mathrm{U}$ enrichment, the total mass fraction of ${ }^{235} \mathrm{U}$ present in the deposit is only $\sim 40$ fg (femtograms $-10^{-15} \mathrm{~g}$ ). While not the focus of this work, these results using the TIPS deposited samples highlights the sensitivity of combining laser ablation sampling with ICP-MS measurements for compositional analysis as well as isotopic analysis.

\section{$\underline{\text { Instrumentation }}$}

The fs-LA-ICP-MS instrumentation used in these measurements is commercially available. The system is supplied by Applied Spectra Inc. of Fremont, CA. The fs-LA-ICP-MS instrument consists of an integration of 2 instruments: a femtosecond laser for ablating the sample and an inductively coupled plasma mass spectrometer for measuring the elemental composition of the ablated material. The femtosecond laser ablation instrument is the Model fsJ200, from Applied Spectra, Inc. using a wavelength of $1030 \mathrm{~nm}$ and a pulse duration of less than $480 \mathrm{fs}$. A laser spot size of $50 \mu \mathrm{m}$ was used throughout these measurements. A repetition rate of $100 \mathrm{~Hz}$ was used with a dwell time of $50 \mathrm{~ms}$, ablating in a square pattern of $90 \mathrm{x} 90 \mu \mathrm{m}$ at a scan rate of $0.150 \mathrm{~mm} / \mathrm{s}$. The carrier gas rate of helium was $0.30 \mathrm{~L} / \mathrm{min}$ and the argon make-up gas rate used was $0.60 \mathrm{~L} / \mathrm{min}$ to introduce the ablated material into the ICP torch. The ICPMS is an Aurora Elite instrument (formerly Bruker Daltronics, Billerica, MA) now available through Jena Analytik (Jena, Germany). The settings for the ICPMS operation are the following: the

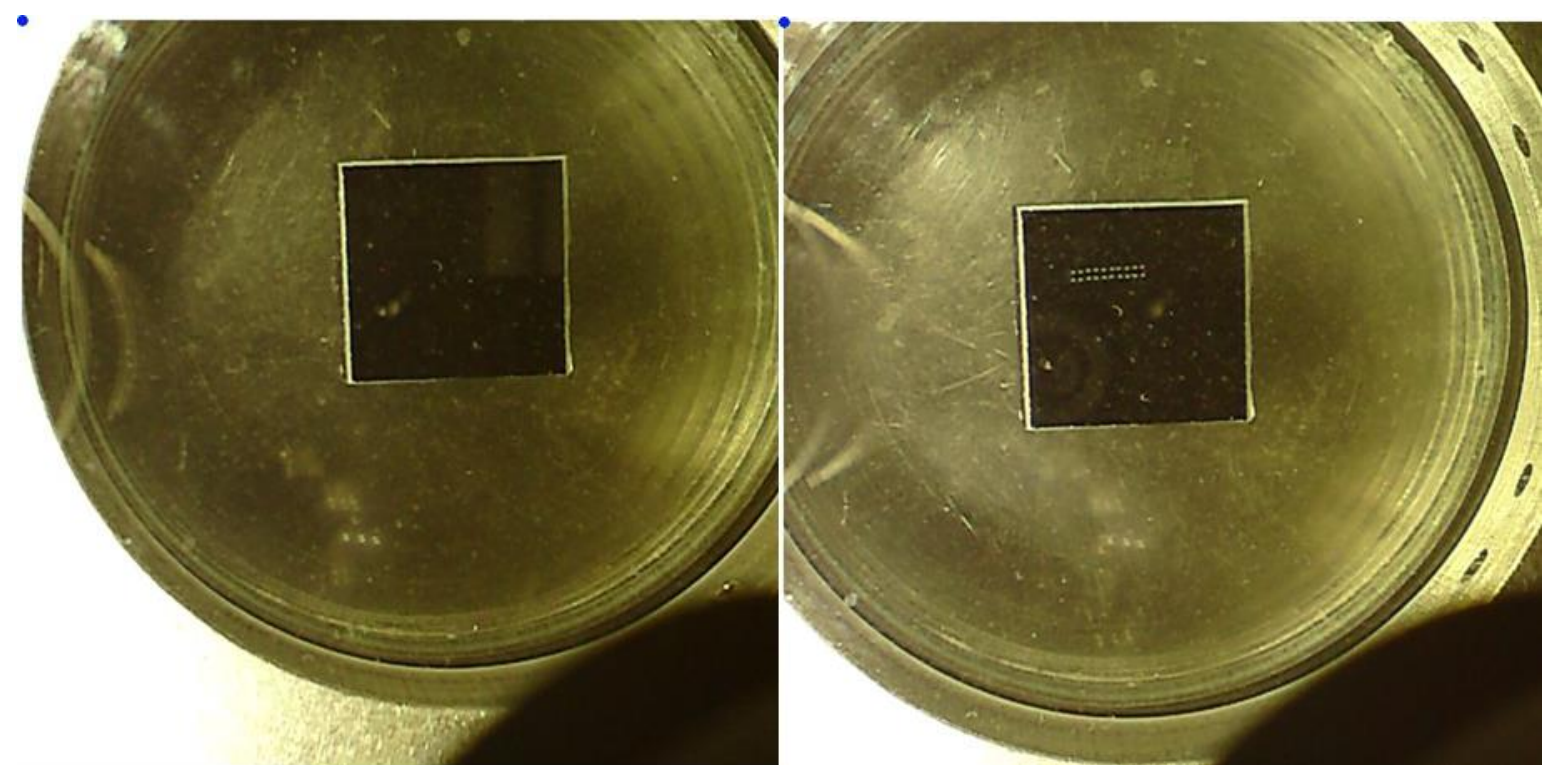

Figure 2. Overview images of the silicon substrate before (left) and after (right) ablation of the deposits. 
plasma was operated at a flow of $18 \mathrm{~L} / \mathrm{min}$, sheath gas flow of $0.80 \mathrm{~L} / \mathrm{min}$, sampling depth of $5.50 \mathrm{~mm}$, power $1.40 \mathrm{~kW}$.

Twenty-nine TIPS spots were analyzed for each uranium enrichment (B-F) containing $0.5,1.5,2,3$, and $15.1 \% 235 \mathrm{U}$ using the fs instrument. Figure 2 shows an overview of the silicon substrate before and after ablation of the dried spot residues and Figure 3 shows a close up view of the deposits before and after ablation.

The ns-LA-ICP-MS instrument used is a commercially available Electro Scientific Industries (ESI) New Wave Research (NWR), NWR 213 Laser Ablation System equipped with a Nd:YAG deep UV $(213 \mathrm{~nm})$ nanosecond laser coupled to a Thermo Scientific iCAP Q ICP-MS. Prior to sample analysis, the ICP-MS parameters were optimized using NIST 612 glass sample. The ICP-MS parameters included a plasma power of $1.5 \mathrm{~kW}$ and argon nebulizer gas flow of $0.5707 \mathrm{~L} / \mathrm{min}$.

Twenty TIPS spots were analyzed per uranium enrichment using the ns laser instrument: $\mathrm{B}, \mathrm{C}, \mathrm{D}, \mathrm{E}$, and F contained $0.5,1.5,2,3$, and $15.1 \%{ }^{235} \mathrm{U}$, respectively. Each spot was ablated (line raster) for 7 seconds in duration, with a spot size of $85 \mu \mathrm{m}$, at $10 \mathrm{~Hz}, 1.8 \mathrm{~J} / \mathrm{cm}^{2}$ and 10 $\mu \mathrm{m} / \mathrm{sec}$. Helium carrier gas was used to deliver the ablated material to the ICP-MS at a flow rate

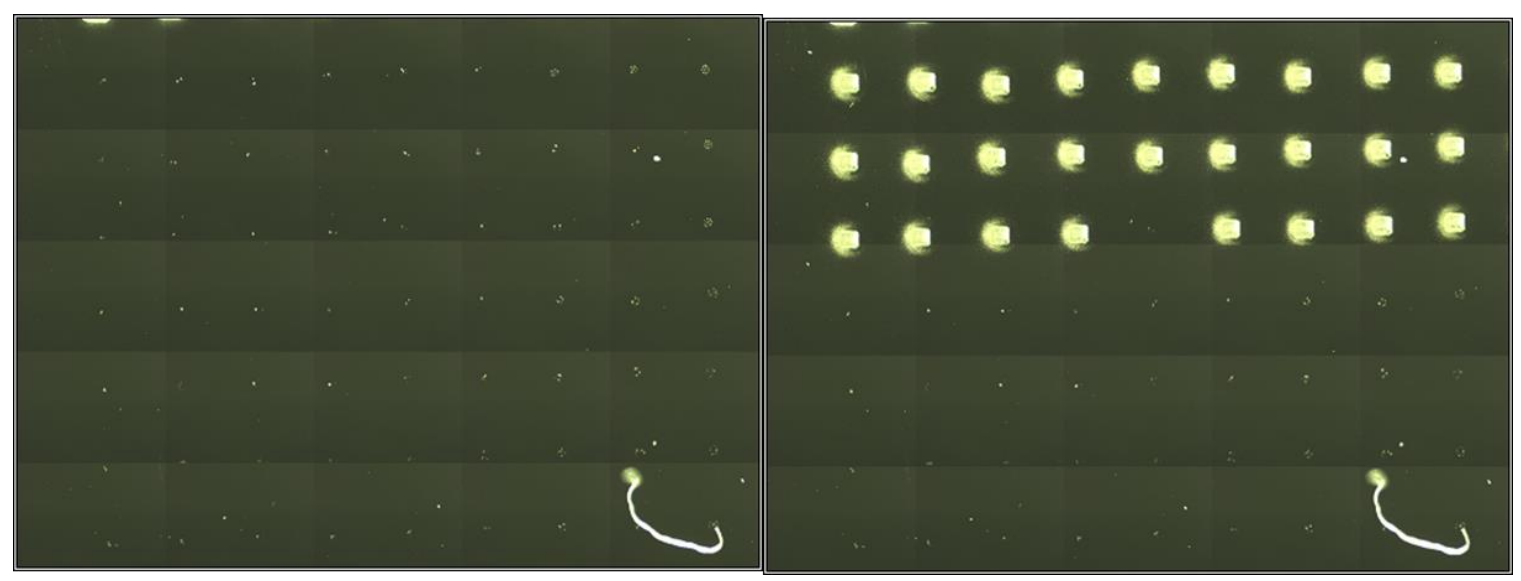

Figure 3. Images of deposits on silicon substrate before (left) and after (right) ablation.

of $1 \mathrm{~L} / \mathrm{min}$. The samples were probed for the isotopic abundances of ${ }^{234} \mathrm{U},{ }^{235} \mathrm{U},{ }^{236} \mathrm{U}$, and ${ }^{238} \mathrm{U}$. Dwell times of 50 milliseconds was used for ${ }^{234} U$ and ${ }^{236} U$ and 10 milliseconds for ${ }^{235} U$ and ${ }^{238} U$. The integration time for analysis was 30 seconds.

\section{RESULTS}

The isotopic measurements for both ASI fs and LANL ns LA-ICP-MS results are shown in Tables 2 and 3. These results show the ${ }^{235} U$, and ${ }^{238} U$ measured intensities which are used to calculate the 235/238 U ratios for each enriched sample deposit. The differences between Table 2 and Table 3 are the number of measurements used in calculating the statistics of standard deviation, and \% RSD for each sample. Each statistical column is defined here: Std Dev is the standard deviation; \% RSD is the percent relative standard deviation where $(($ Std Dev/average $) \times 100)$; \% Difference $=(($ measured theoretical)/theoretical) $\mathrm{x} 100$ ); the bias is (measured - theoretical). 
Table 2 uses all of the measurements collected, ASI 29 deposits, LANL 20 deposits, while Table 3 shows the standard deviation and \%RSD for a subset of the measurements. Both ASI and LANL used a filter of $+/-20 \%$ of the average of the measurements. The reason for

Table 2. Results of fs and ns LA-ICP-MS measurements of enriched uranium deposits on silicon substrate using all measurements for both ASI and LANL.

\begin{tabular}{|c|c|c|c|c|c|c|c|}
\hline ASI & \multicolumn{4}{|c|}{ Theoretical Measured } & \multirow[b]{2}{*}{ \%RSD } & \multirow[b]{2}{*}{ \% Difference } & \multirow[b]{2}{*}{ Bias } \\
\hline$N=29$ & [235U] & $235 / 238$ & $235 / 238$ & Std Dev & & & \\
\hline B & U005 & 0.00503 & 0.00659 & 0.005 & 81.4 & -31.1 & $-1.6 \mathrm{E}-03$ \\
\hline C & U015 & 0.01537 & 0.01730 & 0.005 & 27.5 & -12.6 & $-1.9 E-03$ \\
\hline$D$ & U020 & 0.02044 & 0.03631 & 0.033 & 91.6 & -77.7 & $-1.6 \mathrm{E}-02$ \\
\hline$E$ & U030 & 0.03097 & 0.04358 & 0.039 & 90.3 & -40.7 & $-1.3 \mathrm{E}-02$ \\
\hline $\mathrm{F}$ & U150 & 0.17880 & 0.29430 & 0.451 & 153.1 & -64.6 & $-1.2 \mathrm{E}-01$ \\
\hline ave & & & & 0.107 & 88.77 & -45.3 & $-2.95 E-02$ \\
\hline LANL & \multicolumn{4}{|c|}{ Theoretical Measured } & & & \\
\hline $\mathbf{N}=\mathbf{2 0}$ & [235U] & $235 / 238$ & $235 / 238$ & Std Dev & \%RSD & \% Difference & Bias \\
\hline B & U005 & 0.00503 & 0.00550 & $9 \mathrm{E}-04$ & 16.7 & 9.5 & 4.78E-04 \\
\hline C & U015 & 0.01537 & 0.01690 & 0.002 & 14.4 & 10.0 & $1.53 \mathrm{E}-03$ \\
\hline $\mathrm{D}$ & U020 & 0.02044 & 0.02102 & 0.007 & 33.2 & 2.9 & $5.88 \mathrm{E}-04$ \\
\hline$E$ & U030 & 0.03097 & 0.04076 & 0.019 & 47.3 & 31.6 & $9.79 \mathrm{E}-03$ \\
\hline $\mathrm{F}$ & U150 & 0.17880 & 0.18920 & 0.067 & 35.2 & 5.8 & $1.04 \mathrm{E}-02$ \\
\hline ave & & & & 0.019 & 29.4 & 12.0 & 4.56E-03 \\
\hline
\end{tabular}

removing some of the measurements was due to saturating spikes during the measurements. These spikes in the measurements are evidently a result of a combination of the deposition process as well as the effects of the ablation process itself. Not all of the deposits appeared to be uniform in shape and distribution across the dried residue. In some cases ASI could directly observe the ${ }^{238} \mathrm{U}$ signal saturating with no apparent reason and it was clear, the deposit did not have a saturating level of U present. Both ASI and LANL observed the spiked signals. Although the spike sample removal significantly improves the precision for the smaller subset of measurements as seen in Table 3, the results are still above 10\% RSD. Further study into the cause of these spikes would provide some understanding of the ablation parameters contributing to these spurious signals. However, in the context of these measurements, there is sufficient data to determine the performance of the fs and ns LA-ICP-MS instrumentation. In addition, the ultimate measurement environment would be the U10Mo metal materials and not pg particle-like deposits. Hence, it is reasonable to eliminate these spikes for more accurate comparison of the LA-ICP-MS performance. This assumption is demonstrated for one set of data obtained on a DU10Mo specimen using the fs laser instrument, where 10 shots were measured in duplicate as shown in Table 4. The results for the DU10Mo foil shows precision of less than 2\% RSD for both sets of data with no observed data spikes. This is significantly better than the \%RSD for the TIPS deposit measurements which are above $10 \%$ RSD. The DU10Mo foil measurements 
suggest the deposits as the source of the spiking in those measurements. Overall, the LA-ICP-MS results for both the fs and ns instruments are comparable in this instance.

Table 3. Results of $\mathrm{fs}$ and $\mathrm{ns}$ LA-ICP-MS measurements of enriched uranium deposits on silicon substrate using filtered measurements for both ASI and LANL.

\begin{tabular}{|c|c|c|c|c|c|c|c|}
\hline ASI & & Theoretical & Measured & & & & \\
\hline & N (acquired 29) & $235 / 238$ & $235 / 238$ & Std Dev & $\% \mathrm{RSD}$ & \% Difference & Bias \\
\hline B & 12 & 0.00503 & 0.00499 & $6 \mathrm{E}-04$ & 11.6 & 0.9 & $4.4 \mathrm{E}-05$ \\
\hline C & 14 & 0.01537 & 0.01611 & 0.002 & 11.9 & -4.8 & $-7.4 \mathrm{E}-04$ \\
\hline $\mathrm{D}$ & 5 & 0.02044 & 0.01951 & 0.002 & 10.6 & 4.6 & $9.3 \mathrm{E}-04$ \\
\hline $\mathrm{E}$ & 8 & 0.03097 & 0.02987 & 0.003 & 11.0 & 3.6 & $1.1 \mathrm{E}-03$ \\
\hline $\mathrm{F}$ & 16 & 0.1788 & 0.16146 & 0.025 & 15.8 & 9.7 & 1.7E-02 \\
\hline ave & \multicolumn{2}{|c|}{$38 \%$ useable data } & & 0.007 & 12.2 & 2.8 & 3.74E-03 \\
\hline \multirow[t]{2}{*}{ LANL } & & Theoretical & Measured & & & & \\
\hline & $\mathbf{N}$ (acquired 20) & $235 / 238$ & $235 / 238$ & Std Dev & $\%$ RSD & \% Difference & Bias \\
\hline B & 12 & 0.00503 & 0.00519 & $4 \mathrm{E}-04$ & 8.1 & 3.2 & $1.6 \mathrm{E}-04$ \\
\hline C & 14 & 0.01537 & 0.01639 & 0.002 & 12.0 & 6.6 & $1.0 \mathrm{E}-03$ \\
\hline $\mathrm{D}$ & 9 & 0.02044 & 0.02102 & 0.002 & 11.2 & 2.9 & $5.8 \mathrm{E}-04$ \\
\hline$E$ & 6 & 0.03097 & 0.03175 & 0.004 & 12.3 & 2.5 & $7.8 \mathrm{E}-04$ \\
\hline $\mathrm{F}$ & 18 & 0.1788 & 0.1775 & 0.021 & 11.6 & -0.7 & $-1.3 \mathrm{E}-03$ \\
\hline ave & \multicolumn{2}{|c|}{$59 \%$ useable data } & & 0.006 & 11.0 & 2.9 & $2.5 E-04$ \\
\hline
\end{tabular}

Table 4. Duplicate DU10Mo test foil measurements of 10 shots each for 235/238 ratio using the fs-LA-ICP-MS system

\begin{tabular}{|l|c|c|c|}
\hline & Average & Std Dev & \%RSD \\
\hline U235/U238 & 0.00267 & $4.73343 \mathrm{E}-05$ & 1.77 \\
\hline U235/U238 & 0.00259 & $3.94848 \mathrm{E}-05$ & 1.52 \\
\hline
\end{tabular}
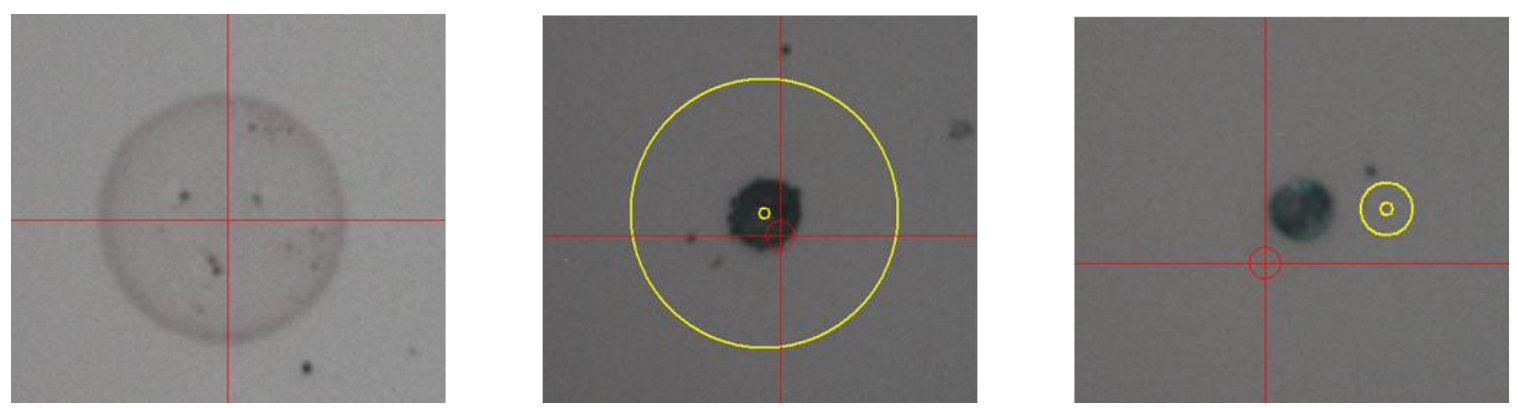

Figure 4. Left, middle, and right represent TIPS spots for A, B, and C, respectively. The outermost yellow circle in the middle picture represents an $85 \mu \mathrm{m}$ spot. Except for $A$, the spots were on the order of 20-30 $\mu \mathrm{m}$ in diameter. A was on the order of 85 um in diameter.

Figures 4 and 5 show images of the LANL TIPS spots prior to ablation. The appearance of the TIPS spots change within a LEU set and between LEU samples as shown in Figures 4 and 
5. The depleted uranium solution (A) has a large coffee ring appearance (Figure 4 left) and is approximately $85 \mu \mathrm{m}$ in diameter. TIPS spots for B-F varied in shape from circular, shown in D and $\mathrm{C}$, to circular with localized deposits (smaller darker circles), shown in B, E, and F. These spots were on the order of 20-30 um in diameter. During ablation, the sample was completely removed. The variability in the spot may contribute to the larger RSDs observed in these measurements compared to homogeneous isotopic samples we have analyzed in the past.

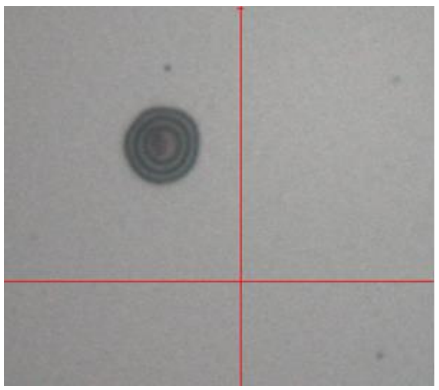

Figure 5. Left, middle, and right represent TIPS
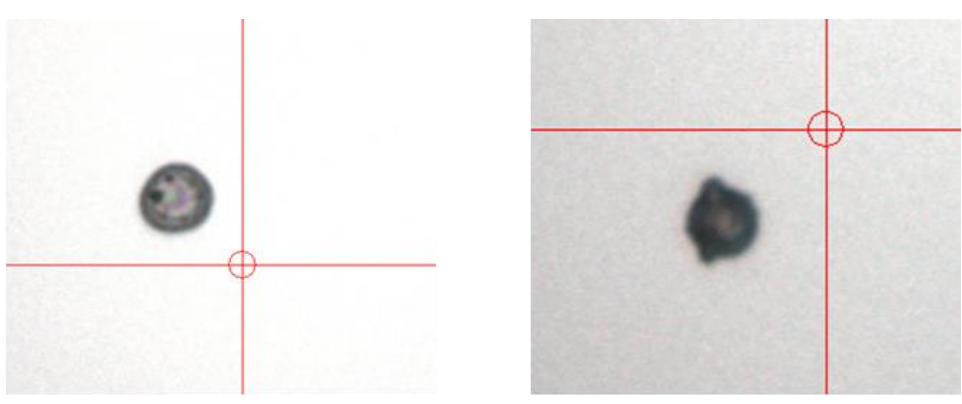

20-30 um in diameter

\section{DISCUSSION}

Overall, in this limited comparison, both the fs and ns LA-ICP-MS instruments demonstrated acceptable performance on both accuracy and precision of the isotopic analyses for $235 / 238 \mathrm{U}$ in the enriched sample deposits. The results of the multiple sampling of the DU10Mo foil with the femtosecond laser system clearly demonstrates the applicability to the expected sample type of metal specimens. Nanosecond and femtosecond LA-ICP-MS performed comparably with nanosecond producing more "usable" data for the deposits. Interestingly, both approaches exhibit near identical filtering of the data. This is most likely a reflection of the differences in ablation characteristics between fs and ns lasers. The lower "usable data" from the fs measurements reflects the higher finesse and gentler sampling of the TIPS deposits compared with the thermal vaporization of the spots with the ns system. In addition, due to funding and time constraints, neither instrumental parameters were fully optimized for ablation of these samples. Both the LANL and ASI ablation parameters were selected after minimal testing and therefore were not optimized for the near particle-like TIPS deposits compared to the actual metal foil. More detailed study with actual metal alloy substrates would be required to fully compare the performance of each ablation approach. Another point of comparison is the price of nanosecond LA-ICP-MS systems compared to femtosecond systems. Nanosecond LA-ICP-MS systems are typically half the cost of femtosecond systems. However, femtosecond lasers are known for their surgical ablation precision, as noted above, due to the direct electronic excitation of the sample whereas nanosecond laser ablation is largely due to thermal mechanisms. In this comparison using these particular samples both pulse durations demonstrated near equivalent data can be produced on either system with respect to accuracy and precision. Either LA-ICP-MS method offers the potential for rapid, accurate and precise isotopic measurements of U10Mo materials whether DU, LEU or HEU. Further comparison between these two ablation approaches with actual materials is warranted in order to identify the optimum method. 


\section{SUMMARY}

The LA-ICP-MS method for isotopic measurements of U10Mo materials can produce quantitative analytical results within minutes of receiving a suitable sample (sample must be able to fit into the ablation chamber and no surface oxidation). This is significantly more rapid than TIMS or even conventional radiometric counting methods. The LA-ICP-MS offers both isotopic and compositional mapping (Mo) capabilities which are important for measuring and directing the reduction efforts of isotopic and elemental heterogeneity in the castings and final foils. Based on the results presented, we are confident either LA-ICP-MS method would have sufficient sensitivity to distinguish between $19.95 \%{ }^{235} \mathrm{U}$ and $20.1 \%{ }^{235} \mathrm{U}$ content in materials of interest, rapidly and with sufficient precision for the production of reactor materials.

\section{ACKNOWLEDGEMENTS}

Funding for this work was provided DOE/NNSA Office of Material Management and Minimization. LA-UR-16-27341 (rev1)

\section{REFERENCES}

1) Irradiation Performance of U-Mo Alloy Based 'Monolithic' Plate-Type Fuel - Design Selection, A.B. Robinson, G.S. Chang, D.D. Keiser, Jr, D. M. Wachs, D.L. Porter, Idaho National Laboratory, INL/EXT-09-16807, August 2009.

2) Demonstration of femtosecond laser ablation inductively coupled plasma mass spectrometry for uranium isotopic measurements in U-10Mo nuclear fuel foils, LA-UR-15-24319, Havrilla, George Joseph, Gonzalez, Jhanis, issued 2015-06-10

3) What is LA-ICP-MS? http://www.appliedspectra.com/technology/LA-ICP-MS.html

4) Femtosecond laser ablation multicollector ICPMS analysis of uranium isotopes in NIST glass, Andrew M. Duffin, Kellen W. Springer, Jesse D. Ward, Kenneth D. Jarman, John W. Robinson, Mackenzie C. Endres, Garret L. Hart, Jhanis J. Gonzalez, Dayana Oropeza, Richard E. Russo, David G. Willingham, Benjamin E. Naes, Albert J. Faheyc and Gregory C. Eiden, J. Anal. At. Spectrom., 2015, 30, 1100.

5) Picoliter Droplet Deposition Using a Prototype Picoliter Pipette: Control Parameters and AApplication in Micro X-ray Fluorescence, Ursula E. A. Fittschen and George J. Havrilla, Anal. Chem. 2010, 82, 297-306

6) NBL Certificate of Analysis CRM U150 for 235 U $15 \%$ enrichment, http://science.energy.gov/ /media/nbl/pdf/pricelists/certificates/CRM_U015_10_Milligram_Sample_Size_March_2008.pdf all other certificates can be found at http://science.energy.gov/nbl/certified-reference-materials/pricesand-certificates/uranium-certified-reference-materials-price-list/ 